\title{
Comparing the Subjective and the Objective Criteria Weighting in Agricultural Water Resources Management
}

\author{
Maryam Hafezparast ${ }^{1, ~ *}$, Shahab Araghinejad ${ }^{2}$, Tatiana Filatova ${ }^{3}$ \\ ${ }^{1}$ Department of Water Engineering, Faculty of Agriculture, Razi University, Emam-Khomeini Highway, Kermanshah, Iran \\ ${ }^{2}$ Department of Irrigation \& Reclamation Engineering, Faculty of Agricultural Engineering \& Technology, College of Agriculture \& Natural \\ Resources, University of Tehran, Karaj, Tehran, Iran \\ ${ }^{3}$ Centre for Studies in Technology and Sustainable Development, Faculty of Management and Governance, University of Twente, Enschede, \\ the Netherlands
}

\section{Email address:}

m.hafezparast@razi.ac.ir (M. Hafezparast), shahab_araghinejad@yahoo.com (S. Araghinejad), T.Filatova@utwente.nl (T. Filatova)

\section{To cite this article:}

Maryam Hafezparast, Shahab Araghinejad, Tatiana Filatova. Comparing the Subjective and the Objective Criteria Weighting in Agricultural Water Resources Management. Hydrology. Vol. 3, No. 4, 2015, pp. 38-46. doi: 10.11648/j.hyd.20150304.11

\begin{abstract}
In this study Integrated Water Resources Management (IWRM) approach is applied to the Aras basin in the North West of Iran to integrate different criteria for demand management and decision making. Coupling between the River Basin Management Model (MIKEBASIN) and Visual Basic Macro in Excel with the use of COM/.Net interface as a Decision Support System (DSS) have done to evaluate the performance of 9 indicators of structural alternatives. The Analytical Hierarchical process, Entropy method and the strategy of equal weighting are compared as three different methods of Subjective, Objective and Equal criteria weighting. The Technique for Order of Preference by Similarity to Ideal Solution (TOPSIS) is used for Multi Criteria Decision Making (MCDM) analysis to determine the best management alternatives. The results show that, the alternative 'Increase water efficiency' and 'Decrease cultivated area' is the most preferred option.
\end{abstract}

Keywords: Integrated Water Resources Management (IWRM), Multi Criteria Decision Making (MCDM), TOPSIS, Aras River Basin

\section{Introduction}

The amount of available water in various regions, such as deserts and tropical forests are quite different. Moreover the variation in the supply of water contains seasonal and annual changes. This means that the uncertainty of water resources is a major challenge for water managers and the community (UN-Water, 2008). In this regard, many of the less developed countries and some developing countries, found that increasing water supply is not the only appropriate solution to address the increasing demands due to population growth, economic and climate pressures. Also improved waste water treatment, water recycling and demand management, should be included in a package of measures to deal with the challenges of improving inadequate water supply (UN-Water, 2008) .Related to this, integrated water resource management (IWRM) approach can be regarded as a process which promotes the development and management of water, land and related resources, in order to maximize the resultant economic and social welfare in an equitable manner without compromising the sustainability of vital ecosystems (UN-Water. GWP, 2007).

Large-scale integrated management of water resources in watersheds with multiple demands from domestic use, and use for industry, agriculture and the environment are investigated with the use of computer simulation software. Some of these software are based on geographic information systems (GIS) that can simulate spatial and temporal water resources planning simultaneously such as MIKE BASIN (DHI, 2003) and WSMDSS (Water Strategy Man, 2002). However, decisions in water management are characterized by multiple objectives and multiple stakeholders (Bressers and Kuks, 2004). This multiplicity overburdens decision makers in finding the best decision; thus, a powerful tool is desired for the final selection. Therefore, many researchers use multi-criteria decision making (MCDM) methods to cope with water-related problems in their studies, as well as in research projects that foresee the development and use of decision support system (DSS) in order to help acquiring sustainable development strategies (Yilmaz and Harmancioglu, 2010). Another important issue is to find effective and efficient methods for decision analysis and DSS 
development. This is because of the complexity of decision analysis, especially in problem analysis and structuring, and consequently in the development of DSSs for such complicated MCDM problems as natural resource management (Liu and Stewart, 2004). The first generation of DSS that combined various components of databases, models and GIS were formed in the mid-1990s. According to Ako et al. (2009) there are two general trends identified currently in the field of mathematical modeling of catchment basins: 1) hydrologic models, to model the behavior of the components of the water cycle from rainfall to runoff, and 2) decision support systems, to model behavior of different processes, like physical, natural, social and economic deliberations at hydrological basin. Generally, the generation of DSS for water management can be classified in three groups according to their emphasis: water quality, water allocation and water life. There is a large body of literature on water resources DSS linked with GIS or MCDM analysis such as Christensen (2004) created a coupling between the River Basin Management Model (MIKE BASIN) and the 3D Hydrological Model (MIKE SHE) with the use of the OpenMI System. Ireson, Makropoulos and Maksimoviv (2006) coupled a strategic scale water resources management simulation model, MIKE BASIN, and a finite difference groundwater model (ASM), as a tool to support decision making in data scarce environments. Leemhuis et al (2009) have developed a Volta Basin Water Allocation System (VB-WAS), a decision support tool that allows assessing the impact of infrastructure development in the basin on the availability of current and future water resources, given the current or future climate conditions. The simulated historic and future discharge time series of the joint climate-hydrological modeling approach (MM5/WaSiM-ETH) serve as input data for a river basin management model (MIKE BASIN). Yilmaz and Harmancioglu (2010) developed a water resource management model that facilitates indicator-based decisions, with respect to environmental, social and economic dimensions in a multiple criteria perspective, for the Gediz River Basin in Turkey. Mathematical models are suitable tools to support the implementation of IWRM (Humberto et.al, 2009). So that in this paper we follow the trend of mathematical methods using decision support systems in water allocation and try to solve the water scarcity in the Aras basin with management alternatives under following steps. 1) Combination of software tools (Mike basin and Visual Basic Macro in Excel) to simulate system operation and computing system performance indices such as supply reliability, resiliency and vulnerability, 2) Application of IWRM DSS in a data scarce region, 3) Compare different method of Subjective, Objective and Equal criteria weighting for importance of performance indices, 4) Exploration of climate change coping strategies for Iran on the example of Aras watershed.

\section{Case-Study: The Aras River Basin}

Aras River Basin is located in the northwest of Iran. The region covers 39534 square kilometers. The latitudes of the area are between 38 to 40 northern degrees. This basin is bounded at the west and north side by the state borders of Iran with Turkey, Armenia and Azerbaijan. On the south and east, the Aras Basin is bounded by the Urmia Lake Basin and the Balharoud River Basin. The entire population of the Aras Basin in the year 2000 was approximately 2.4 million people, involving nearly 3.7 percent of all the population of Iran and the population growth rate was $0.6 \%$. In this regard, with 63 persons per sq. Km, the Aras River Basin is one of the most populated regions within Iran. Agricultural and industrial developments in this basin were in recent years substantial. Some important industrial and agricultural production centers of Iran like the agriculture and animal husbandry in the Moghan plain, industrial activities in the outskirt of Ardabil, the Jolfa free merchant area, and the Poldasht, Aslandooz, Khoy and Marand cities are all located in this basin. Therefore, it is necessary to carry out comprehensive studies for the possibility of reducing development impacts in this basin. Ardabil, Julfa, Khoi, Marand and Pars-Abad are the main cities here. The geographical location of the Aras River Basin in Iran is represented in (Figure1).

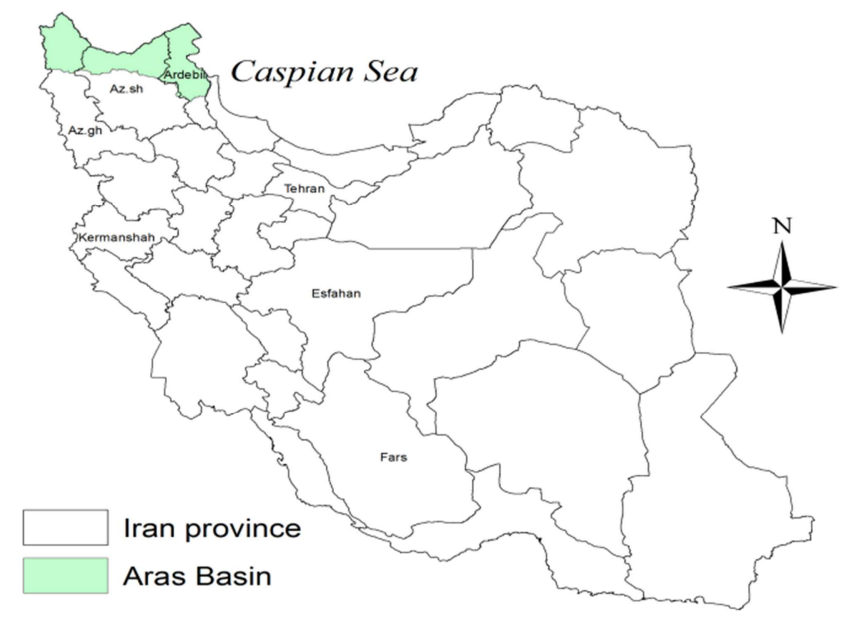

Fig. 1. Aras river basin in the map of Iran.

\section{Methodology}

The flowchart of methodology contains three main parts: data base, analysis and decision making (Figure2). The topology of water system such as rivers, reservoirs, water demands, and transmission links are the essential inputs into MIKE GIS. In the analysis phase, the problem statement regarding the relation between water demand and supply based on the IWRM approach is described. The different scenarios of climate change and population growth are defined and then the proposed structural and nonstructural alternatives are determined to be evaluated in the water allocation model MIKE BASIN. The quantitative outputs of MIKE BASIN are automatically analyzed in visual basic macro excels and the performance matrix calculated in the third part of DSS. As an aid for decision making this calculation has been done to choose the best alternative with the MCDM method. 


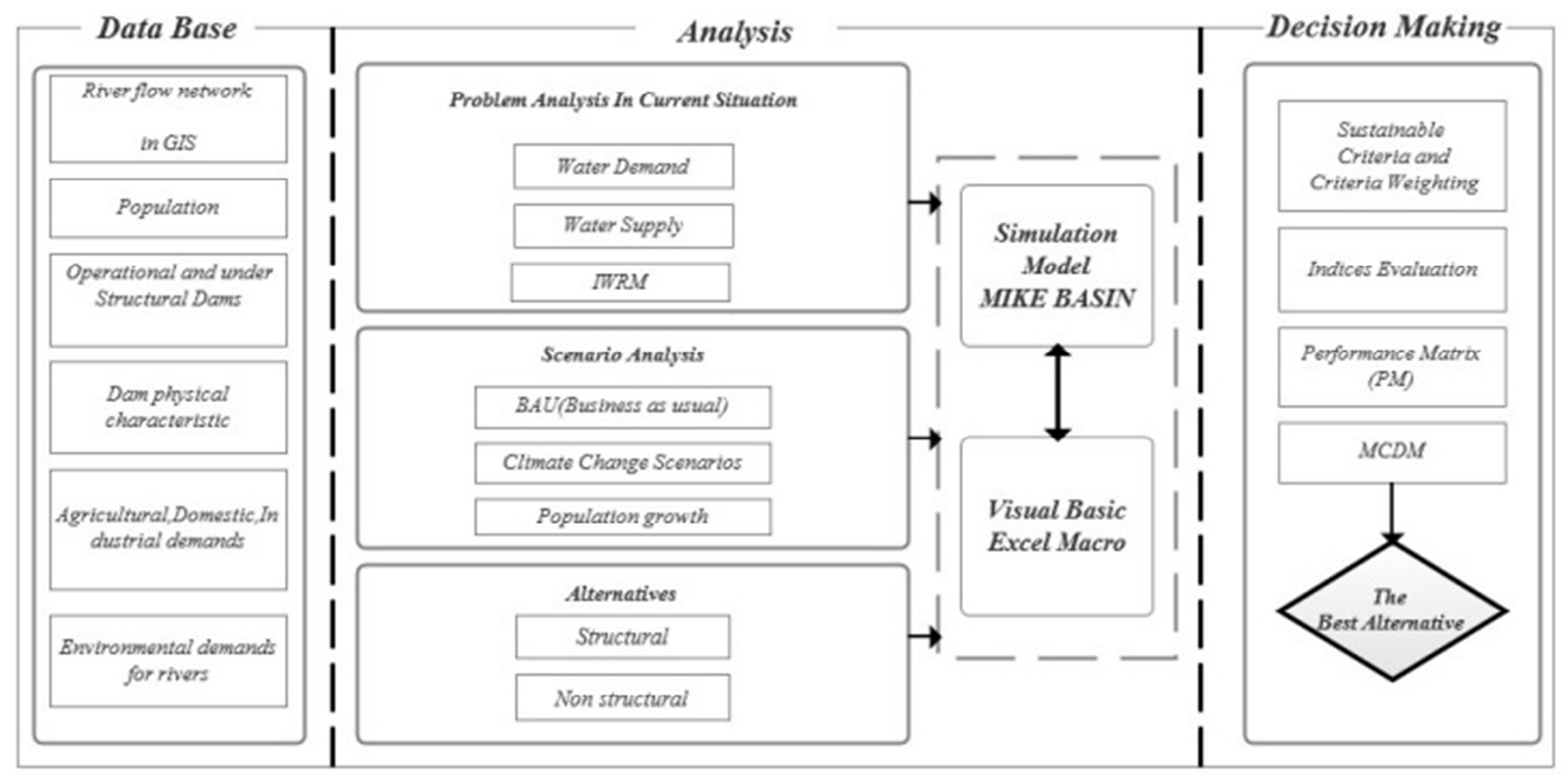

Fig. 2. The flowchart of methodology.

\subsection{Mike Basin}

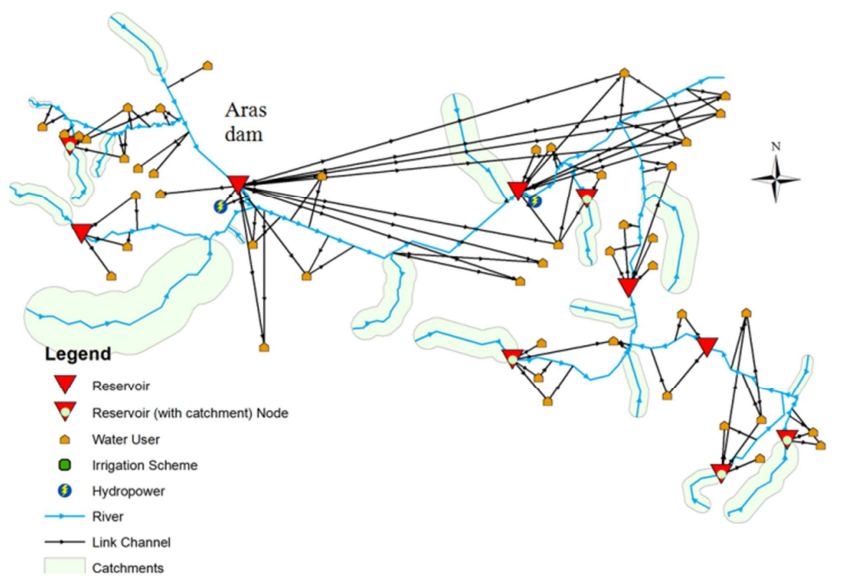

Fig. 3. Aras basin schematic in Mike Basin.

MIKE BASIN is a multi-purpose, GIS-based river basin simulation package. Designed for analyzing water sharing problems and environmental issues at international, national and project scales (Danish Institute of Hydrology, 2003). MIKE BASIN couples the power of Arc GIS with comprehensive hydrologic modeling to provide basin-scale solutions. MIKE BASIN embeds another DHI GIS Extension, Temporal Analyst, which implies that an abundance of tools for spatial associations, analysis and presentation of time series data are available. Moreover, the MIKE BASIN code is open-ended, and through the extensive COM/.NET interface all input, output and allocation rules can be accessed and manipulated, allowing for extensive customization and even allowing for full integration of MIKE BASIN in external modeling systems. Examples are economic or ecologic models, customized pre- and postprocessors and tailor made decision support systems. The MIKE BASIN schematic in which the Aras River Basin is represented is given in Figure 3.

\subsection{Input Data}

\subsubsection{Proposed Alternatives}

Alternatives are the structural and non structural ways to decrease the adverse effects of future scenarios like climate change, population growth, rapid civilization, depletion of aquifers, water and conflict, and water quality, etcetera. The alternatives that are considered (see Table 1) have the aim to increase the water supply with respect to irrigation efficiency and decrease the demand. The performance of these alternatives differs under different hydro-climatically scenarios. The losses from the irrigation canals in Iran are about $30 \%$. Consequently this subject is considered in all the scenarios in relation to irrigation demands. Alternative A1 shows that with proper canal maintenance the losses can be decreased gradually to $15 \%$ (Mahabghods, 2010). In reaction to low water efficiency of irrigation in Aras basin, the farmers in the basin is offered some significant incentives with subsides to construct water - saving irrigation technologies (e.g. drip irrigation systems). The policy is to promote irrigation efficiency which is currently estimated at approximately 30\% (Mahabghods, 2010). In accordance with this policy, alternative A2 based on improvement of irrigation methods and educating farmers is developed to increase water efficiency by 10\% (Mahabghods, 2010). These water demand changes are applied to the model simulation. Since for water transfer to a receiving basin the general satisfaction of the people within the basin of origin is 
important and the majority of people in the basin of origin are opposed to transfer of water to other watersheds, the alternative A3 evaluates a lack of water transfer to Urmia Lake. The alternative A4 proposes to decrease the cultivated area in 5 agricultural demand areas such as 'Baron', 'Sattarkhan', 'Ardabil', 'Ghorichay' and 'Sabalan' to receive $10 \%$ less water in the long term. This alternative was formulated in response to the high water deficit, and the discontent of farmers, based on field studies (Mahabghods, 2010). The first results of calculating supply indicators for alternative A3 show that it hasn't great effects on Aras basin sustainability. On the other hand, alternative A3 wasn't used in the Alternative combination like 'Decrease losses and increase water efficiency' (A5), 'Decrease losses and Decrease cultivated area' (A6) and 'Increase water efficiency and decrease cultivated area' (A7) to evaluate the results of aggregated management plans.

Table 1. Evaluating management alternatives.

\begin{tabular}{ll}
\hline Alternatives & Definition \\
\hline A0: Do nothing & No additional measures to the current system \\
A1: Decrease in canal & Canal maintenance, water distribution \\
losses & maintenance \\
A2 :Increase water & Chang water irrigation systems and increase \\
efficiency & farmer knowledge using water in the best way \\
A3: lack of water & don't transfer to Urmia lake \\
transfer to Urmia lake & \\
A4 :Decrease cultivated & Decrease cultivated area with high water unmet \\
A5: (A1+A2) & Decrease losses and increase water efficiency \\
A6:(A1+A4) & Decrease losses and Decrease cultivated area \\
A7:(A2+A4) & $\begin{array}{l}\text { Increase water efficiency and decrease } \\
\text { cultivated area }\end{array}$ \\
\hline
\end{tabular}

\subsubsection{Climate Scenarios}

Reference scenarios are based on hydrological -meteorological changes and simulation of the effects on the water balance of supply and demand. The three reference scenarios with a combination of water availability and demand scenarios have been simulated and in addition, the project of water transfer to Urmia River Basin in the reference scenarios is considered. The business as usual scenario (BAU), includes maintaining the long-term average of water availability and demand. The monthly stream flow data for 30 years, from 1972 to 2002 from Aras Dam operation is extended into the simulation period (2002-2032). The starting point of the simulation period is 2002 which is the last year of data records. Water demand calculations assuming constant cropping patterns and fixed irrigation areas are calculated for all the irrigation districts.

The pessimistic scenario (PES) refers to the loss of available water resources and increasing demand. Zeeb (2010) has done a study on the effects of climate change on the Kura-Aras Basin and the study estimated a reduced precipitation and stream flow, and an increased monthly mean temperature. The PES is based on the A2 climate scenario for the entire study area, Kura-Aras River Basin, and shows that the rivers' flow will decrease $6.7 \%$ in 2030 and $14.5 \%$ by 2070 and $24.4 \%$ from 2100 . Temperature increases in the summer month average to 4.8 to $5.7 \%$ by the year 2100 and the average annual rainfall especially in the summer months will reduce 8 to $27 \%$ by 2100 . Thus, in this scenario the monthly stream flow in the time series used in the BAU scenario is reduced by $6.7 \%$ in the next 30 years. The domestic water demand is increased based on population growth rate equal to $0.6 \%$ in 2002 and the irrigation area, crop pattern and irrigation demand due to the lack of increase in temperature and decrease in precipitation for the next 30 years in the study described was considered fixed.

The Optimistic scenario (OPT) indicates an increase in water availability and a constant water demand. In this scenario, the rivers' flow in the BAU scenario is increased $6.7 \%$ and the temperature, precipitation and irrigation areas are constant.

\subsection{Indices Definition}

Table 2. Evaluating criteria and indicators.

\begin{tabular}{|c|c|c|}
\hline Criteria & Indicators & Definition \\
\hline \multirow{4}{*}{$\begin{array}{l}\text { Environmental } \\
(\mathrm{EN})\end{array}$} & $\begin{array}{l}\text { Agriculture } \\
\text { sustainability } \\
\text { (EN1) }\end{array}$ & $\begin{array}{l}\text { The temporal aggregation of } \\
\text { supply/demand ratio time series for } \\
\text { irrigation demands according to } \\
\text { performance measures }\end{array}$ \\
\hline & $\begin{array}{l}\text { Environmental } \\
\text { sustainability } \\
\text { (EN2) }\end{array}$ & $\begin{array}{l}\text { The temporal aggregation of } \\
\text { supply/demand ratio time series for } \\
\text { environmental demands according } \\
\text { to performance measures }\end{array}$ \\
\hline & $\begin{array}{l}\text { Irrigation water } \\
\text { use (EN3) }\end{array}$ & $\begin{array}{l}\text { Percentage of potential surface } \\
\text { water allocated to agricultural } \\
\text { demands (The effect of agricultural } \\
\text { return flow on water quality) }\end{array}$ \\
\hline & $\begin{array}{l}\text { Unavailable } \\
\text { water (EN4) }\end{array}$ & $\begin{array}{l}\text { The amount of water that removes } \\
\text { from the last point of Aras } \\
\text { river.(Annual average in MCM) }\end{array}$ \\
\hline \multirow{3}{*}{ Social (SO) } & $\begin{array}{l}\text { Domestic water } \\
\text { reliability (SO1) }\end{array}$ & $\begin{array}{l}\text { Reliability of domestic demands } \\
\text { that ratio of supply to demand } \\
\text { equals to } 1\end{array}$ \\
\hline & $\begin{array}{l}\text { Irrigation (SO2) } \\
\text { unmet }\end{array}$ & $\begin{array}{l}\text { Annual unmet for agricultural } \\
\text { demands(MCM) }\end{array}$ \\
\hline & $\begin{array}{l}\text { Reliability of } \\
\text { water transfer } \\
\text { (SO3) }\end{array}$ & $\begin{array}{l}\text { Reliability of water transfer that the } \\
\text { ratio of supply to demand equals to } \\
1\end{array}$ \\
\hline \multirow{2}{*}{$\begin{array}{l}\text { Economic } \\
(\mathrm{EC})\end{array}$} & $\begin{array}{l}\text { Ratio of benefit } \\
\text { to cost }(\mathrm{EC} 1)\end{array}$ & $\begin{array}{l}\text { The Ratio of benefit to cost of } \\
\text { management alternatives for the } \\
\text { simulation period }\end{array}$ \\
\hline & $\begin{array}{l}\text { The total value } \\
\text { of (EC2) } \\
\text { production }\end{array}$ & $\begin{array}{l}\text { Annual total production } \\
\text { value(Million Rial) }\end{array}$ \\
\hline
\end{tabular}

To provide management alternatives, nine indicators based on sustainability of environmental, social and economic criteria are considered (Table2). It should be noted that the MIKE BASIN outputs are analyzed automatically by the link between the MIKE BASIN and EXCELL and calculated indicators by Visual Basic Macro programming. This means that the developed indicators are based on the quantitative assessments of alternatives. To evaluate alternatives, the annual average values of time series that are achieved for the simulation period are used for some indicators such as EN3, EN4, SO2, EC2. The EN3 indicator shows the percentage of surface water that is allocated to the agricultural demands to 
the total water surface. The EC1 indicator shows that the benefit to cost ration is varying. It is obtained by dividing the total benefits by the total costs.

Reliability, Resilience and Vulnerability (RRV) are used as indices to evaluate the performance of a water resources system in meeting the water demand (Hashimoto et al., 1982; Fowler et al., 2003). This process for each index, $C$, is shown in the time series with $C_{t}$ and $\mathrm{t}$ is the duration of the simulation. To calculate these parameters, the upper limit and lower limit of an acceptable range should be defined. These values are determined by the judgment of decision makers. $\mathrm{SO} 1, \mathrm{SO} 3$ are the indicators that are achieved from the reliability index of which the equation is shown in Equation 1.

$$
R S(C)=\frac{\text { Number of times a satisfactory } C_{t+1} \text { values follows an unsatisfactory } C_{t} \text { value }}{\text { Total number of unsatisfactory values }}
$$

Vulnerability is a statistical indicator that measures the extent and the duration of unsatisfactory values. In this study it is defined as expected extent-vulnerability, and the durations of failures are excluded (Equation3).

$$
V U(C)=\frac{\left(\text { individual extents of } C_{t}\right. \text { failures }}{\text { Total number of individual extent of } C_{t} \text { failures }}
$$

The sustainability index that ranges from zero to one as the worst to the best value was calculated by multiplying the values of reliability, resiliency, and (1-vulnerability). For sustainability, reliability and resiliency indices should be the maximum and minimum vulnerability. In this way, the agricultural sustainability index (EN1) and environmental sustainability index (EN2) are calculated according to Eqs.4 and 5, respectively. The supply/demand ratio (S/D) used for irrigation districts and environmental demands for EN1, EN2. The satisfactory range is selected to be between 0.8 and 1 for agricultural and 1 for environmental demands respectively.

$$
\begin{gathered}
E N 1=R E_{(S a / D a)} * R S_{(S a / D a)} *\left(1-V U_{(S a / D a)}\right) \\
E N 2=R E_{(S e / D e)} * R S_{(S e / D e)} *\left(1-V U_{(S e / D e)}\right)
\end{gathered}
$$

\subsection{Weighting the Criteria}

There are several methods to determine the weights of criteria which can be used in various ways for different policy evaluation purposes. Alternative weighting methods could result in different ranking. Thus, it is important to test how sensitive the outcome of MCDM is with respect to the weighting procedure. Some methods like analytic hierarchy process (AHP) made via preference elicitation technique and it's based on DMs experiences, knowledge and perception of the problem. However, the DMs usually have different idea and can rarely reach an agreement on the relative importance of criteria (Yilmaz and Harmancioglu 2010). So that, in this paper, three different weighting methods include subjective, objective and equal weighting method compared. 1) Analytic hierarchy process (AHP) depends on DMs experience as a subjective method 2) Entropy method (EM) as an objective method, and 3) The strategy of equal criteria weighting.
Reliability (RE) is calculated as a probability of any $C_{t}$ value to be within the range of values considered satisfactory (Equation1).

$$
\mathrm{RE}(\mathrm{C})=\frac{(\text { Number of Satisfactory } \mathrm{Ct} \text { values })}{(\text { Total number of simulated periods })}
$$

Resilience (RS) describes the speed of recovery from an unsatisfactory condition. It is the probability that a satisfactory value $C_{t+1}$ will follow an unsatisfactory $C_{t}$ value (Equation2).

\subsubsection{Entropy Method (EM)}

Entropy was first introduced into information theory by Shannon (1948). It has been widely used in the engineering, socioeconomic and other fields. According to the basic principles of information theory, information is a measure of system's ordered degree, and the entropy is a measure of system's disorder degree. To determine criteria weights by the entropy value $E_{j}$, the PM matrix should be normalized by (Equation6). Then a new matrix containing the values of each alternative in each criterion is obtained (Equation7).

$$
\begin{aligned}
& r_{i j}=\frac{a_{i j}}{\sum_{i=1}^{n} a_{i j}}, j=1,2, \ldots, m \\
& R=\left[\begin{array}{llll}
r_{11} & r_{12} & \ldots & r_{1 m} \\
r_{21} & r_{22} & \ldots & r_{2 m} \\
\ldots & \ldots & \ldots & \ldots \\
r_{n 1} & r_{n 2} & \ldots & r_{n m}
\end{array}\right]
\end{aligned}
$$

The values in matrix $R$ are considered as the 'emission power' of each criterion $C_{j}(j=1,2, \ldots, m)$ and are used to calculate an entropy value $E_{j}$ as (Equation8).

$$
E_{j}=-k \sum_{i=1}^{n} r_{i j} \ln r_{i j}, j=1,2, \ldots, m
$$

$K$, is constant and equal to $K=1 / \ln n$, so that $0<E_{j}<1$. The degree of divergence $\left(d_{j}\right)$ of the values in each criterion is obtained as (Equation9).

$$
d_{j}=1-E_{j}, j=1,2, \ldots, m
$$

This means that the greatest divergent in the initial scores $a_{i j}$ of each alternative $A_{i}(i=1,2, \ldots, n)$ in each criterion $C_{j}$ is the maximum value of $d_{j}$ and has been the most important 
for criteria $C_{j}$. If $d_{j}$ is considered as the specific measure of inherent contrast of the criterion $C_{j}$, the final relative weights for each criteria is calculated by (Equation10).

$$
w_{j}=d_{j}\left[\sum_{i=1}^{m} d j\right], j=1,2, \ldots, m
$$

\subsubsection{Analytic Hierarchy Process (AHP)}

AHP is the well-known type of subjective weight-assessing method that was introduced by Saaty (1970). He suggests two techniques for obtaining the information on preference: pair wise comparison and Eigen-vector computing. In fact, we can get these values by a direct-rating process or compute them through the least-square method, without affecting the validity of the AHP model (Gwo-Hshiung et al, 1998). The first-level criteria were compared between-each-other depending on importance and matrix, $P$, is derived in which

$P_{i j}$ Are described as presenting the relative importance of the $i$ th criterion with respect to $j$ th criterion (Equation11).

$$
p=\left[\begin{array}{cccc}
1 & p_{12} & \ldots & p_{1 m} \\
p_{21} & 1 & \ldots & p_{2 m} \\
\ldots & \ldots & \ldots & \ldots \\
p_{m 1} & p_{m 2} & \ldots & 1
\end{array}\right]
$$

In the process of comparison, just the upper triangular matrix is determined and the lower triangular is defined as (Equation12).

$$
P_{i j}=\frac{1}{p_{i j}}
$$

The normalized pair wise comparison matrix is derived by dividing each element in $\mathrm{P}$ by its column sum (Equation13). Then, the principal eigenvector $(\lambda)$ that defines the criteria weight vector $(\mathrm{W})$ is obtained by averaging across the rows of $\mathrm{X}$ (Equation14), where the wj $(\mathrm{j}=1, . . \mathrm{m})$ shows the relative weights among the criteria that are compared, and the sum of criteria weights is 1 .

$$
\begin{gathered}
X=\left[\begin{array}{cccc}
1 / \sum_{m=1}^{m} P_{m 1} & \cdot & \cdot & p_{1 m} / \sum_{t=1}^{m} p_{t m} \\
\cdot & \cdot & \cdot & \cdot \\
p_{m 1} / \sum_{m=1}^{m} p_{m 1} & \cdot & \cdot & 1 / \sum_{t=1}^{m} p_{t m}
\end{array}\right]=\left[\begin{array}{cccc}
x_{11} & \cdot & \cdot & x_{1 m} \\
\cdot & \cdot & \cdot & \\
x_{m 1} & \cdot & \cdot & x_{m m}
\end{array}\right](13) \\
W=\frac{1}{m}\left[\begin{array}{c}
\sum_{m=1}^{m} x_{1 m} \\
\cdot \\
\sum_{t=1}^{m} x_{m t}
\end{array}\right]=\left[\begin{array}{c}
w 1 \\
\cdot \\
\cdot \\
w_{m}
\end{array}\right]
\end{gathered}
$$

Further, the consistency of criteria weights should be checked. Saaty (1980) proved that for a consistent reciprocal matrix, the largest Eigen value is equal to the number of comparisons, or $\lambda_{\max }=n$. Then he gave a measure of consistency, called Consistency Index as deviation or degree of consistency using the following formula (Equation15 and 16) and also proposed that this index in comparison with the Consistency index (Table3), is called Random Consistency Index $(R I)$. If the value of Consistency Ratio is smaller or

\begin{tabular}{|c|c|c|c|c|c|c|c|}
\hline n & 3 & 4 & 5 & 6 & 7 & 8 & 9 \\
\hline 1.4457 & 1.4217 & 1.3334 & 1.2525 & 1.1045 & 0.8832 & 0.5381 & RI \\
\hline \multicolumn{8}{|c|}{$C I=\frac{\lambda_{\max }-n}{n-1}$} \\
\hline & & & $=\frac{C l}{D}$ & & & & (16) \\
\hline
\end{tabular}
equal to $10 \%$, the inconsistency is acceptable. If the Consistency Ratio is greater than $10 \%$, the subjective judgment should be revised.

Table 3. Random Consistency Index $(R I)$.

\subsection{Multi Criteria Decision Making (MCDM)}

Multi Criteria Decision-Making (MCDM) methods are gaining importance as potential tools for analyzing complex real problems due to their inherent ability to judge different alternatives on various criteria for possible selection of the best/suitable alternative (s). In this study the TOPSIS method (Hwang and Yoon, 1980) for ranking the alternatives is used. The basic concept of this method is that the selected alternative should have the shortest distance from the ideal solution and the farthest distance from the negative-ideal solution in some geometrical sense. Below we will explain its steps.

(1) Calculate the normalized decision matrix. The normalized value $\mathrm{X}_{\mathrm{ij}}$ is calculated as (Equation17).

$$
r_{i j}=\frac{X_{i j}}{\sqrt{\sum_{i=1}^{m} X_{i j}^{2}}}, j=1,2, \ldots, m
$$

(2) Calculate the weighted normalized decision matrix. The weighted normalized value $v_{i j}$ is calculated as (Equation18).

$$
v_{i j}=w_{j} x_{i j}, i=1, \ldots, m, j=1, \ldots, n \text {. }
$$

Where $w_{j}$ is the weight of the $i$ th attribute or criterion, and $\sum_{j=1}^{n} w_{j}=1$.

(3) Determine the positive ideal and negative ideal solution and calculate the separation measures, using the n-dimensional Euclidean distance. The separation of each alternative from the ideal and negative ideal solution is given 
as (Equation19 and 20).

(4) Calculate the relative closeness to the ideal solution as (Equation21) Rank the preference order. For ranking alternatives using this index, we can rank alternatives in decreasing order.

$$
\begin{aligned}
& s_{i^{+}}=\left[\sum_{j}\left(v_{i j}-v_{+j}\right)^{2}\right]^{0.5} \\
& s_{i^{-}}=\left[\sum_{j}\left(v_{i j}-v_{-j}\right)^{2}\right]^{0.5} \\
& c_{i^{+}}=\frac{s_{i^{-}}}{s_{i^{+}}+s_{i^{-}}}
\end{aligned}
$$

\section{Results and Discussion}

The Performance Matrix (PM) is formed on the basis of the 9 indicators and 8 alternatives (including the alternative of do nothing, A0). For the three scenarios, BAU, PES and OPT, three PMs are produced, which do not only provide indicators for evaluation but also support eventual decision-making processes on infrastructure (Table 4). The values of indicators across all scenarios show that the alternatives 'Do nothing' (A0) and 'Don't transfer to Urmia Lake' (A3) are less effective than others. More dominant are the combined alternative such as (A7) Increase water efficiency and decrease cultivated area', (A6) 'Decrease losses and decrease cultivated area', and (A5) 'Decrease losses and increase water efficiency'. Thus, a diversified portfolio of IWRM measures is always preferable. This result holds under all scenarios and various weighting methods (Table 5). Compare three different method of subjective, objective and equal criteria weighting shows that, the Alternative A7 received top rank 5 times out of 9 simulations, A6 got ranked top 3 times out of 9, with A5 selected only once as the top. This implies that the portfolio of such measures as 'Decrease cultivated area' (in A7 and A6), 'Increase water efficiency' (components of A7 and A5) and 'Decrease losses' (A5 and A6) is the most robust one across all considered scenarios of the future regardless of the weighting

\begin{tabular}{|c|c|c|c|c|c|c|c|c|c|c|}
\hline \multirow{2}{*}{ Scenario } & \multirow{2}{*}{$\begin{array}{l}\text { Criteria } \\
\text { Indicators } \\
\end{array}$} & \multicolumn{3}{|c|}{ Environmental } & \multicolumn{3}{|c|}{ Social } & \multicolumn{3}{|c|}{ Economic } \\
\hline & & EN1 & EN2 & EN3* & EN4* & SO1 & SO2* & SO3 & EC1 & EC2 \\
\hline \multirow{8}{*}{ BAU } & A0 & 0.14 & 0.117 & 0.400 & 0.378 & 0.97 & 396.8 & 0.967 & 1.26 & 39520 \\
\hline & A1 & 0.169 & 0.120 & 0.422 & 0.457 & 0.981 & 259.1 & 0.972 & 1.30 & 41227 \\
\hline & $\mathrm{A} 2$ & 0.167 & 0.114 & 0.335 & 0.468 & 0.981 & 183.3 & 0.975 & 1.14 & 32754 \\
\hline & A3 & 0.149 & 0.116 & 0.408 & 0.407 & 0.970 & 363.7 & - & 1.27 & 39920 \\
\hline & A4 & 0.167 & 0.122 & 0.403 & 0.379 & 0.979 & 280.7 & 0.967 & 1.26 & 39344 \\
\hline & A5 & 0.189 & 0.129 & 0.344 & 0.539 & 0.987 & 113.1 & 0.978 & 1.16 & 33640 \\
\hline & A6 & 0.180 & 0.117 & 0.419 & 0.459 & 0.989 & 153.2 & 0.972 & 1.30 & 40926 \\
\hline & A7 & 0.183 & 0.113 & 0.332 & 0.471 & 0.991 & 105.5 & 0.975 & 1.13 & 32434 \\
\hline \multirow{8}{*}{ OPT } & A0 & 0.162 & 0.117 & 0.387 & 0.430 & 0.976 & 331.8 & 0.972 & 1.48 & 40323 \\
\hline & A1 & 0.173 & 0.143 & 0.4 & 0.516 & 0.985 & 215.4 & 0.978 & 1.51 & 41763 \\
\hline & A2 & 0.178 & 0.140 & 0.318 & 0.528 & 0.984 & 155.1 & 0.978 & 1.32 & 33138 \\
\hline & A3 & 0.158 & 0.128 & 0.389 & 0.463 & 0.976 & 307.7 & - & 1.49 & 40618 \\
\hline & A4 & 0.174 & 0.120 & 0.384 & 0.414 & 0.985 & 221.8 & 0.972 & 1.48 & 40077 \\
\hline & A5 & 0.240 & 0.150 & 0.326 & 0.600 & 0.989 & 85.3 & 0.981 & 1.34 & 33974 \\
\hline & A6 & 0.183 & 0.138 & 0.397 & 0.520 & 0.993 & 116.9 & 0.978 & 1.51 & 41352 \\
\hline & A7 & 0.188 & 0.138 & 0.314 & 0.532 & 0.993 & 82.5 & 0.978 & 1.32 & 32744 \\
\hline \multirow{8}{*}{ PES } & A0 & 0.132 & 0.095 & 0.418 & 0.322 & 0.959 & 495.8 & 0.953 & 1.19 & 38299 \\
\hline & A1 & 0.155 & 0.108 & 0.44 & 0.392 & 0.924 & 326.9 & 0.969 & 1.23 & 40368 \\
\hline & A2 & 0.157 & 0.109 & 0.350 & 0.402 & 0.967 & 242.5 & 0.969 & 1.09 & 32030 \\
\hline & A3 & 0.133 & 0.090 & 0.423 & 0.350 & 0.959 & 459.4 & - & 1.19 & 38757 \\
\hline & A4 & 0.144 & 0.105 & 0.417 & 0.322 & 0.964 & 388.0 & 0.953 & 1.19 & 38016 \\
\hline & A5 & 0.178 & 0.114 & 0.363 & 0.470 & 0.975 & 154.1 & 0.975 & 1.11 & 33139 \\
\hline & A6 & 0.172 & 0.116 & 0.440 & 0.394 & 0.978 & 216.2 & 0.969 & 1.23 & 40112 \\
\hline & A7 & 0.172 & 0.120 & 0.349 & 0.404 & 0.979 & 153.8 & 0.969 & 1.09 & 31837 \\
\hline
\end{tabular}
technique.

Table 4. Performance matrix of alternative and indices.

\begin{tabular}{|c|c|c|c|c|c|c|c|c|c|}
\hline Scenario & BAU & & & OPT & & & PES & & \\
\hline Rank & equal Weighting & Entropy & AHP & equal Weighting & Entropy & AHP & equal Weighting & Entropy & AHP \\
\hline 1 & A7 & A7 & A6 & A6 & A7 & A5 & A7 & A7 & A6 \\
\hline 2 & A6 & A5 & A5 & A7 & A5 & A7 & A6 & A5 & A5 \\
\hline 3 & A5 & A6 & A7 & A5 & A6 & A6 & A5 & A6 & A7 \\
\hline 4 & $\mathrm{~A} 2$ & $\mathrm{~A} 2$ & $\mathrm{~A} 2$ & $\mathrm{~A} 2$ & $\mathrm{~A} 2$ & $\mathrm{~A} 2$ & $\mathrm{~A} 2$ & $\mathrm{~A} 2$ & $\mathrm{~A} 2$ \\
\hline 5 & Al & A3 & Al & A4 & A3 & A1 & A1 & A3 & A1 \\
\hline 6 & A4 & A1 & A4 & A1 & A1 & A4 & A3 & A1 & A4 \\
\hline 8 & A0 & $\mathrm{A} 0$ & $\mathrm{~A} 0$ & $\mathrm{~A} 0$ & $\mathrm{~A} 0$ & $\mathrm{~A} 0$ & A0 & $\mathrm{A} 0$ & $\mathrm{~A} 0$ \\
\hline
\end{tabular}

Indicator to be minimized ${ }^{*}$

Table 5. Rank of alternatives with different criteria weights. 
Due to the increase in available water in the OPT scenario, similar results appear with better performance than BAU scenario and in the PES scenario with reduced water availability and increased demand the alternatives have lower performance results than in the BAU and OPT scenarios.

EN1 is an indicator that is obtained through the overlap of reliability, resilience and vulnerability of irrigation demand (supply/demand ratio). It varies between 0 (worst performance) and 1 (best performance). It improves $31 \%, 48.1 \%$ and $34.8 \%$ in scenarios BAU, OPT and PES respectively. This improvement is based on A7 and A5 implementation. The EN2 indicator that shows the sustainability of environmental demands, can improve $0.88 \%, 28.2 \%$ after A5 implementation in BAU and OPT scenarios and 33.3\% after A7 in PES scenario, It means that alternative A7 is so useful in reduced water availability and increased demand. After implementation of A7, the most improvement in the EN3 indicator that shows the rate of surface water use in agricultural demands is $21.32 \%, 21.5 \%$ and $22.73 \%$ in scenarios BAU, OPT and PES respectively. Minimizing the amount of water that removes from the last point of Aras river help to keep more water for water management and this goal is obtained by the EN4. In this way, A7 has the most percent of water removes and the best results for alternative A0 and A4. The SO1 and SO3 indices show the reliability of domestic demands and water transfer to Urmia Lake and in all the alternatives have a high performance. The average annual agricultural unmet demand that shows $\mathrm{SO} 2$ index, decreased by alternative A7 includes 'Increase water efficiency' and 'Decrease cultivated area'. This reduction equal to $73.4 \%$, $75.13 \%$ and $68.98 \%$ in scenarios BAU, OPT and PES respectively maximum performance of $B / C$ related to EC1 index, respectively, reaches to $1.5,1.3,1.23$ in OPT, BAU and PES scenarios with implementation of the alternatives, A1 'Decrease in canal losses' and A6 'Decrease losses' \& 'Decrease cultivated area'.

In summary, considering different criteria weighting methods, A7 is identified as the most preferred alternative in MCDM method that refers to aggregation of alternatives $(\mathrm{A} 2+\mathrm{A} 4)$.

\section{Conclusion}

The infrastructural resources in the Aras basin (Table1) include 10 dams under operation and construction, and the demands include 20 agricultural, 7 domestic, 5 industrial and 11 environmental demands and also water transfer to the Urmia lake water basin. The results of EN1 and EN2 indicators show that, these values are so far from the satisfactory range. So the main points are derived from the analysis of meteorological - hydrological scenarios indicate that the Aras basin, for each of the three scenarios, is vigorously under water stress in dry years and water demand management policies to solve the water crisis to achieve sustainable development are necessary.

Based on the indicators taking into account environmental, social and economic criteria, the decrease of cultivated area and the increase of irrigation efficiency are the most effective management strategies in the Aras basin. In the other hand, Equal criteria weighting proposed to implement alternative A7 in BAU and PES scenarios and A6 in OPT scenario. Due to the effect of indicators in watershed sustainability, Objective criteria weighting, in all the scenarios, A7 is the best alternative to implementation and finally, based on decision makers experience, the Subjective weighting method, the alternative A6 in the BAU and PES scenarios and A5 in the OPT scenario selected as the best one.

Since the water transfer project to Urmia Lake will be implemented, the results show that, 300 million cubic meter of water transfer, has no serious adverse effects on the Aras basin water management. In this regard, the developed methodology is a valuable tool for the evaluation of water resources allocation systems and the implementation of integrated water resources management in the Aras basin. The Mike basin software is also a useful tool for planning and management of water resources with very powerful GIS data bases. To compare this paper with all papers that are reviewed in literature the most important points are 1) The management alternatives are based on field studies that governance did in Aras basin (mahabghods,2010). 2) The quantitative indicators are based on environmental, social and economical criteria of Aras basin. 3) Calculating 9 indicators in 3 scenarios and 8 alternatives is so difficult in handy work so in this paper we coupled Mike basin to Visual Basic Macro in Excel with the use of the COM/.Net, and choose the best alternative in each scenario by MCDM analysis, made a decision support system.4) Compare different Subjective, Objective and Equal criteria weighting methods, help decision makers to choose the best alternative in each scenario. Future directions of research are 1) Investigation of climatic scenarios based on General Circulation Models (GCM). 2) Adding more indicators in quality of water and soil and 3) Application of other weighting criteria and MCDM methods.

\section{References}

[1] Ako, A. A., Eyong, G. E. T., \& Nkeng, G. E. (2009). 'Water Resources Management and Integrated Water Resources Management (IWRM) in Cameroon', Journal of Water Resources Management (24): 871-888.

[2] American Society of Civil Engineers (ASCE). 1998. 'Sustainability Criteria for Water Resources Systems'. (Task Committee on Sustainability Criteria, Water Resources Planning and Management Division, ASCE and Working Group, UNESCO/IHP IV Project M-4.3). ASCE, Reston, VA.

[3] Bressers, H. and S. Kuks (2004). Governance of Water resources. In: Integrated governance and water basin management, Bressers H. and S. Kuks [eds.], Kluwer Academic Publishers.

[4] Christensen, F. 2004. 'Coupling between the River Basin Management Model (MIKE BASIN) and the 3D Hydrological Model (MIKE SHE) with use of the OpenMI System'. 6th International Conference on Hydroinformatics. Singapore. 
[5] Churchman, C. W., Ackoff, R. L., Arnoff, E. L., 1957. Introduction to Operations Research. John Wiley, New York.

[6] Danish Institute of Hydrology. MIKE BASIN.2003. A versatile decision support tool for integrated water resources management and planning, DHI Water and Environment, Denmark.

[7] Danish Institute of Hydrology. MIKE BASIN.2003. Manuals and Documentation. http:// www. dhisoftware. com/ mikebasin/ index.htm.

[8] Densham P. J. and Goodchild M. F.1989.Spatial decision support systems: a research agenda. Proceedings of GIS/LIS'89.ACSM, Bethesda Maryland, pp.707-16.

[9] Eckenrode, R. T. 1965. Weighting multiple criteria. Management Sc. 12, 180-192.

[10] Hashimoto, T., Stedinger, J. R., and Loucks, D. P., 1982, Reliability, resiliency and vulnerability criteria for water resource system performance evaluation, Water Resources Research, 18(1), 14 - 20, doi: 10.1029/ WR018i001p00014.

[11] Humberto, S. H., Ignacio, R. M. D., María Teresa, A. H.,and Alfredo, G. O., 2009. Mathematical modeling for the integrated management of water resources in hydrological basins. Water Resources Management (23): 721-730.

[12] Hwang, C. L; Yoon, K. 1981. Multiple Attribute Decision Making: Methods and Applications. New York: Springer-Verlag.

[13] Ireson, A., Makropoulos, C., Maksimovic, C., 2006. Water Resources Modeling under Data Scarcity: Coupling MIKE BASIN and ASM Groundwater Model. Journal of Water Resources Management (20):567-590.

[14] Leemhuis, C., Jung, G., Kasei, R., Liebe, J., 2009. The Volta Basin Water Allocation System: assessing the impact of small-scale reservoir development on the water resources of the Volta basin, West Africa. Journal of Advances in Geosciences (21):57-62.
[15] Dingfei Liu, Theodor J. Stewart. 2004. Integrated object-oriented framework for MCDM and DSS modelling. Decision Support Systems 38(3): 421-434.

[16] Mahabghods consulting engineering. 2010. Update the State Water Plan Aras, Sefidrood, Gorganrood, Atrak, Urmia watersheds. Aras synthesis Report.

[17] Reitsma, R. F., 1996. Structure and support of water-resources management and decision-making. Journal of Hydrology (177). Iss.3-4: 253.

[18] Saaty, T. 1994. The Analytic Hierarchy Process. Wiley, New York.

[19] Shannon Claude, E., 1948. A Mathematical Theory of Communication. Bell System Technical Journal 27 (3): 379-423.

[20] Tzeng, G-H., Chen, T-Y., Wang, J. C., 1998. A weight assessing method with habitual domains. European Journal of Operational Research, 110: 342-367.

[21] UN-Water. 2008. Status Report on Integrated Water Resources Management and Water Efficiency Plans.

[22] UN-Water. GWP. 2007. Roadmapping for Advancing Integrated Water Resources Management (IWRM) Processes.

[23] Yilmaz, B., Harmancioglu, N. B., 2010. An indicator based assessment for water resources management in Gediz River Basin, Turkey. Journal of Water Resources Management 24(15):4359-4379.

[24] Water Strategy Man project, EU Contract No. EVK1-CT-2001-00098(2002-2005) http://environ.chemeng.ntua.gr/wsm.

[25] Zeeb, S., 2010. Adaptation to Climate Change in the Kura-Aras River Basin. Snapshot Draft for Discussion. 